\title{
A KEY FOR HYPOXIA GENETIC ADAPTATION IN ALPACA COULD BE A HIF1A TRUNCATED bHLH PROTEIN DOMAIN.
}

Daniel Moraga $\mathrm{M}^{1}$, Fernando A. Moraga $\mathrm{C}^{2}$ \& Felipe Figueroa ${ }^{1}$

Escuela de Medicina, Facultad de Ciencias de la Salud, Universidad de Tarapacá Facultad de Medicina, Universidad Católica del Norte

Corresponding author: Felipe Figueroa. Email: ffigueroauta@gmail.com.

\section{Abstract}


Animals exposed to hypoxia, triggers a physiological response via Hypoxia Inducible Factors (HIF1). In this study, we have evidenced the existence of genetic events that caused the loss of most of the bHLH domain in HIF1A proteins borne by Alpaca and other members of the Cetartiodactyla superorder. In these truncate domains, some stop codons are found at identical nucleotide positions in both, Artiodactyls and Cetaceans, indicating that mutations originating the truncated domains occurs before their divergence about 55 million years ago. The relevance of this findings for adaptation of Alpacas to hypoxia of high altitude conditions are discussed.

Key words: Hypoxia, HIF1A, bHLH domain, Alpacas

\section{Introduction}

Camelids and remaining even-toed ungulates (artiodactyls) together with whales and dolphins (cetaceans) are grouped in the superorder Cetartiodactyla, Price et al. (2005). Alpacas (Lama pacos Linnaeus, 1758), reclassified as Vicugna pacos by Kadwell et al. (2001), is one of the four species of South American camelids. Llamas (Lama glama L) along with Alpacas are domestic species, while guanacos (Lama guanicoe Miller 1776) and vicuñas (Vicugna vicugna Molina 1782) are wild species. 
During the evolution of South American camelids, they developed physiological adaptations to the cold environments and food shortages typical of environments of high-altitude hypoxia, 3000 meters over the sea level Wheeler (2012). Hypoxia is a situation in which there is a reduction in the availability of oxygen to tissues and cells. Different physiological adaptations for living in hypoxia has been described in Llamas. These, include higher affinity of hemoglobin for $\mathrm{O}_{2}$, slight increase in blood hemoglobin concentration, high muscle myoglobin concentration, a more efficient $\mathrm{O}_{2}$ extraction at tissue levels, high lactic dehydrogenase activity, and less muscularized pulmonary arteries, Llanos et al. (2011a, 2011b).

Hypoxia is associated with developmental, physiological environmental and pathophysiological conditions as ischemia, arthritis, inflammation, chronic lung disease, stroke, heart disease and cancer, Semenza (1999). A particular archetype of hypoxia is that associated with high altitudes (hypobaric hypoxia). As a consequence of this type of hypoxia, humans and animals triggers an acute (AMS) or chronic (CMS) response depending on the time of exposure. AMS is established when a person is exposed for a short period to hypobaric hypoxia and develops signs of a headache, fatigue, sleep disorder, gastrointestinal disorders or vertigo, Davis et al. (2017). CMS, also known as Monge's disease, may be come about when a person lives for a long time at high altitude, reviewed by Villafuerte \& Corante (2016). Around 1.2 to $33 \%$ of populations living at high altitude suffer from CMS depending on factors such as age, sex, high and the origin of the population, Azad et al. (2017). One important sign of CMS is the elevation of the hematocrit and the number of erythrocytes (polycythemia). While increasing the amount of hemoglobin in the blood could be a beneficial adaptation to hypoxia, excessive erythrocytosis results in a higher blood viscosity, which affects tissue blood flow and oxygen supply Prchal (2010).

The Hypoxia Inducible Factors (HIFs) proteins are transcription factors that play a key role in the homeostasis of oxygen in animals, Rytkonen \& Storz (2011). HIFs proteins are basic Helix-Loop-Helix-PER-ARNT-SIM (bHLH-PAS) proteins distinguish by being both ubiquitously expressed and signal-regulated or constitutively active and tissue specific, Button et al. (2017). HIFs proteins form 
heterodimeric complexes that are composed of alpha $\mathrm{O}_{2}$-labile subunit, either HIF1A, EPAS1 (HIF2A $\alpha$ ) or HIF3A and one stable $\beta$-subunit HIF1 $\beta$ also known as Aryl hydrocarbon receptor nuclear translocator (ARNT). In normoxia conditions in presence of $\mathrm{O}_{2}$, the HIFA subunits are modified by the HIF-specific prolylhydroxylases (PHD), causing proteasomal degradation mediated in part by the von Hippel-Lindau suppressor protein (VHL), Button et al. (2017), Fribourgh \& Partch (2017).

Ethiopians in Africa, Han in Asia and Andean populations of South America have been the most investigated to elucidate the adaptive mechanisms to CMS of high altitude human populations, Villafuerte \& Corante (2016). Several of these studies have demonstrated the existence of a genetic adaptation to hypoxia in Tibetan populations, for review see Murray et al. (2018). Genetic adaptation to hypoxia conditions has also been evidenced in goat, dog, and sheep that live in highaltitudes, Song et al. (2016); Wang et al. (2014); Zhang et al. (2014).

In the present study, we have investigated the phylogenetic relationships and genetic structures of the HIF1A proteins carried by members of the superorder Cetartiodactyla. During our investigation, we discovered the existence of a genetic event that caused the loss of most of the bHLH domain in the proteins borne by the Alpaca and other members of the Cetartiodactyla superorder. As the mutations affect, both the Artiodactyls and Cetaceans, we postulate that the mutation occurred before their divergence about 55 million years ago, Gingerich \& Uhen (1998). The relevance of these findings for genetic adaptation of Alpacas to hypobaric hypoxia of high altitude conditions is discussed.

\section{Material and methods}

\section{The species dataset.}

The complete set of HIF1A protein sequences of the superorder Cetartiodactyla included in the present study belong to 38 species of families from orders Artiodactyla and Cetacea. The species have been identified by a 4-digit acronym, 
in which the first two letters correspond to the name of the genus and the last two, to the name of the species. These acronyms will be used from here on.

The families of the Order Artiodactyla are Camelidae: Vicugna pacos (Vipa); Camelus bactrianus (Caba); Camelus dromedarius (Cadr) and Camelus ferus (Cafe). Bovidae: Bison bison (Bibi); Bos taurus (Bota); Bos mutus (Bomu); Ovis aries (Ovar); Pantholops hodgsonii (Paho); Capra hircus (Cahi) and Bos grunniens (Bogr). Cervidae: Odocoileus virginianus texanus (Odvi). Suidae: Sus scrofa (Susc).

The families of order Cetacea are Balaenopteridae: Balaenoptera acutorostrata scammoni (Baac). Phocoenidae: Neophocaena asiaeorientalis (Neas). Physeteridae: Physeter catodon (Phca). Delphinidae: Orcinus orca (Oror) and Tursiops truncates (Tutr). Monodontidae: Delphinapterus leucas (Dele). Lipotidae: Lipotes vexillifer (Live).

\section{Selection of HIF1A proteins.}

Proteins containing PAS domains borne by Cetartiodactyls species were retrieved from the NCBI GenBank (www.ncbi.nlm.nih.gov). We used a PSI-BLAST search with three iterations and the Alpaca EPAS1 protein (accession number XP_015105262.1) and the sequences were subsequently grouped with the help of the CLANS program, Zimmermann et al. (2017). Later, only HIF1A proteins were selected and aligned with the help of the Clustal Omega program and further analyzed.

\section{Dendrogram construction.}

Evolutionary relationships were evaluated by genetic distance methods using the neighbor-joining algorithm for phylogenetic tree construction of the Mega 7 program, Kumar et al. (2016). The parameters pairwise deletion and p-distance model were used. Bootstrap test of phylogeny was performed with 1000 replicates.

\section{Results}


As the EPAS1 (HIF2A) protein has been implicated in the genetic adaptation to the hypoxia conditions in humans and animals living in the plateau altitudes, Murray et al. (2018); Song et al. (2016); Wang et al. (2014); Zhang et al. (2014), we first searched in the Vicugna pacos NCBI database for corresponding EPAS1 protein sequences. A single sequence was found (accession number XP_015105262.1) which then we use as a query, to perform a BLAST search for PAS-containing proteins on the whole Cetartiodactyla NCBI DataBank. A total of 959 sequences were identified and retrieved, 46 of which correspond to Alpacas. In the present study, we restricted the genetic analysis to the 38 HIF1A proteins. Remaining analysis of others PAS proteins will be published somewhere else.

The set of the 38 HIF1A proteins sequences included in the present study are, from the order Artiodactyla, (1 Vipa sequence; 1 Caba; 2 Cafe; 1 Cadr; 2 Bibi; 2 Bota; 2 Bomu; 2 Ovar; 3 Paho; 4 Cahi; 3 Bogr; 2 Odvi; 1 Susc) and from the order Cetacea (2 Baac; 1 Neas; 3 Phca; 1 Oror; 1 Tutr; 1 Dele; 3 Live).

The alignment of the sequences is shown in Figure 1 and in the Supplementary $A$ section. In Figure 1 the alignment include the first 480 amino acids of 12 representative HIF1A protein sequences encompassing the bHLH, PAS and PAS 3 domains. In the Supplementary A section, the whole set of the 38 full length HIF1A proteins is included. The alignment of the protein sequences reveals that they can be divided according to their length, into two categories which we designate as Long and Short ( $L$ or $S$ in Figure 1 and Supplementary A section). The former start with a Met amino acid at position 1, 4 or 14 of the alignment, the latter with a Met amino acid at position 63. Of the all sequences, 28 belong to the $L$ type, while the remaining 10 correspond to the $S$ type. Sequences of $L$ or $S$ type are present in both, Artiodactyla and Cetacea orders. For example, among the $\mathrm{S}$ type sequences are those borne by the Artiodactyls Vipa, Cafe, Cadr, Cahi and Bibi and by the Cetacean Baac, Tutr, Phca, Odvi, and Live. A similar situation occurs with the $L$ type sequences (Figure 1). When in the alignment more than $1 \mathrm{HIF} 1 \mathrm{~A}$ proteins are borne by members of one single species, the sequences may be either of the same types or from a different one. Examples from the first category are the 4 Paho sequences which all belong to the $L$ type. Alternatively, out of the four Cahi 
sequences, 3 are $\mathrm{L}$ and $1 \mathrm{~S}$, or the Phca sequences ( $2 \mathrm{~L}$ and $1 \mathrm{~S}$ ) and Baac sequences (1L and $1 \mathrm{~S}$ ).

In a characteristic HIF1A protein, four domains are present. A basic Helix-LoopHelix amino-terminal domain (bHLH), is followed by two PER-ARNT-SIM domains (PAS) and then by two transactivation domains, one $\mathrm{NH} 2$ - terminal domain and one $\mathrm{COOH}$ - terminal domain. In the set of sequences that we have analyzed, we have realized that the short sequences differ from the long ones, in that they are devoid of most of the bHLH domain. In fact, only the second helix region is present. In the long type, the entire bHLH domain contained 50 amino acids, while the short type contains only 13 residues. Thus, in the short, only amino acids corresponding to the second helix region are present (numbering according to Zhou et al.1997).

Sequence analysis at the DNA level allows getting an insight into the genetic events that generated the short HIF1A proteins. The alignment of the sequences is shown in Figure 2 and in the Supplementary B section. In Figure 2 the alignment include the full bHLH domain of 15 representative HIF1A protein sequences. In the Supplementary B section, the whole set of the 34 full length bHLH domain sequences is included. In the alignment, the conserved sequence CGAAAAGAG in position 37-39, encodes for the first 3 residues (RKE in Figure 1), of the bHLH domain of HIF1A proteins. Although the next 5 'upstream 16 positions are also well preserved, then the sequences are segregated into two clusters. One of the clusters, in which all short sequences are grouped, is distinguish from the other group in having a high nucleotide variability and been very Thymine rich at its 5 'end.

In the alignment, the Cetacean sequences Dele, Phca, Tutr, Odvi and Baac and the Artiodactyls Cahi and Bibi conform an identical or nearly identical compact group and in all seven sequences a TAA stop codon is present at position 29 of the alignment. All these sequences are short and the presence of the stop codon by itself explain the fact of the shortening of the HIF1A protein that they borne. Sequence Live, which also have de TAA stop codon in the Thymine rich stretch is different from all other short nucleotide sequences. Finally, camelids Vipa, Cadr 
and Cafe conform a second conserve cluster, with a stop codon TAA at position 2 in the alignment.

\section{Discussion}

When animals are acute or chronically exposed to hypobaric hypoxia, they trigger a hypoxic response via Hypoxia Inducible Factor (HIF) proteins that function as transcriptional complexes. HIF proteins are heterodimers with 2 chains, HIF-alfa and HIF-beta. A full hypoxic response requires dimerization, nuclear translocation and binding of HIF proteins to p300-CBP proteins, important for maximal transcriptional activation, Arany et al. (1996).

The analysis of the sequences HIF1A proteins in Cetartiodactyla reveals that the Alpaca protein lacks most of the bHLH domain, present in the generality of bHLH PAS family proteins, Wang et al. (2014). These proteins share a common structure that includes DNA Binding domain $(\mathrm{bHLH})$, followed in tandem by PAS domains (PAS-A and PAS-B) and variable domains of transactivation or transrepression.

The alignment in Figure 2 provides several distinctive features which give some insight into the evolution of the nucleotide bHLH encoding domain. First, all but one of the seven sequences at the top part of the Figure 2 are identical in 5 thymine rich stretch. The only exception is the Odvi sequence. Second, all the seven sequences contain the stop codon TAA at position 29 of the alignment. Third, in the Neighbor joining (NJ) tree shown in Figure 3, the seven sequences are grouped into two branches. One contains the three artiodactyl sequences (Cahi, Odvi and Bibi) and the second all the four cetacean bHLH sequences. As a whole, these three characteristics seem to indicate that in the evolution of HIF1A protein, the advent of the short protein version was a unique mutational event which gave rise to a bHLH pseudogene. Also, the data indicate that this mutational event occurred before the divergence of artiodactyls and cetaceans, about 55 Mya Gingerich \& Uhen (1998).

Additional information is provided by the camelid species, one Alpaca (Vipa) and the two camel sequences (Cadr and Cafe), which all three share the 5 'thymine richness nucleotide stretch with the other short sequences. The three sequences 
also show a TAA stop codon, but this is located 27 codons upstream of one detected in the previous seven ones. All three camelids sequences are almost identical each other which indicate that their differentiation with the rest of the sequences occur during the 40-45 Millions year of evolution in the plains of North America and before the separation of North and South American camelids, which occurs some 3 Mya, Wheeler, 2012). The short Bibi sequence is also 5 thymine rich and also contain a stop codon, but this is instead TAG and is located 4 codons upstream of the TAA in sequences at the top of Figure 2. Finally, the $S$ type Live sequence is similar to all other short sequences in having both the TAA stop codon and in being Thymine rich at its $5^{\prime}$ end. A particular feature of the sequence is the fact that it shows at the 5 'end some similarities with the three of the long sequences Ovar, Bibi and Bogr. Taking this similarity into account, we can speculate that perhaps the original mutation originating the bHLH pseudogene could have occurred in a long sequence which was rich in thymine at its 5 'end.

A phylogenetic tree based on bHLH nucleotide sequences shows that they are grouped with two exceptions, into two major clades depending on whether they are derived from coding sequences for long or short HIF1A proteins (Figure 3). In one of the clades are found all but one of the long sequences. In the other clade are found all but one of the short sequences. The exceptions are $L$ Paho and the $S$ Live sequences, which incongruous locations can be explained by their differences at a stretch from codon 20 to 30 in the alignment.

In the clade of the long sequences, three different branches can be found. In the first are all Bovidae sequences, such as Bota and Ovar and one of the two sequences of Paho. The second branch contains the long sequences derived from the Camelidae Caba, the Cervidae Neas, the Suidae Susc and all the long sequences derived from cetaceans. In a third branch are the 5'Thymine rich long Bovidae Ovar, Bibi and Bogr sequences and the incongruous Lipotidae Live short sequence. In the clade of the short sequences, two main branches can be found. One contains the Camelids, Cadr, Cafe and Vipa, the Bovids Bibi and the incongruous Paho long sequence. The others are all the seven sequences described above. 
Initial studies by Reisz-Porszasz et al. (1994) showed that cutting the bHLH domain does not affect the dimerization and nuclear translocation of HIF1A, but it diminished its binding to DNA, impelling the normal hypoxic response. Further studies have corroborated these conclusions (Semenza et al.1997; McGuire et al. 2001; Huang et al. 2012). Then, according to these findings, we conclude that the hypoxic-response in Alpacas is diminished due to the adaptive loss of part of bHLH domain of HIF1A proteins. Consequently, Alpacas are genetically adapted to live in a low oxygen tension environment, without the negative consequences of a full hypoxic response, such as AMS and CMS. Interestingly, we have found that the absence of most the bHLH domain in the HIF1A protein of the only South American camelid included in the present study, also seems to exist in other members of the Cetartiodactyla superorder. Thus, in addition to the Alpaca, truncated bHLH domain in HIF1A proteins, are also possible to be found among goats, old world camelids and cetaceans. The main conclusion of this finding is that the mutation(s) that gave rise to truncated bHLH domains in some Cetartiodactyla HIF1A proteins, occurred around 55 Mya, before the divergence of Artiodactyla and Cetaceans Gingerich \& Uhen (1998).

\section{Acknowledgments.}

We thank Mr. Ricardo Reyes for the help in editing the manuscript. There are none funding sources.

\section{References.}

Arany, Z, Huang, L. E; Eckner, R; Bhattacharya, S; Jiang, C; Goldberg, M. A; Bunn, H. F \& Livingston D. M. An essential role for p300/CBP in the cellular response to hypoxia. Proc. Nat. Acad. Sci., 93: 12969-12973, 1996.

Azad, P; Stobdan, T; Zhou, D; Hartley, I; Akbari, A; Bafna, V \& Haddad, G. G. High-altitude adaptation in humans: from genomics to integrative physiology. J. Mol. Med. 95: 1269-1282, 2017. 
Button, E. L; Bersten, D. C \& Whitelaw, M. L. HIF has Biff - Crosstalk between HIF1a and the family of bHLH/PAS proteins. Exp. Cell. Res. 356:301-308, 2017.

Davis, C \& Hackett, P. Advances in the prevention and treatment of high altitude illness. Emergency Med. Clinic 35: 241-260, 2017.

Fribourgh, J. L \& Partch, C. L. Assembly and function of bHLH-PAS complexes. Proc. Natl. Acad. Sci. USA. 14: 5330-5332, 2017.

Gingerich, P. D \& Uhen, M. D. Likelihood estimation of the time of origin of Cetacea and the time of divergence of Cetacea and Artiodactyla. Paleontol. Electronica 2:1-47, 1998.

Huang, N, Chelliah, Y, Shan, Y, Taylor, C. A, Yoo, S. H, Partch, C, Green, C. B, Zhang, H \& Takahashi, J. S. Crystal structure of the heterodimeric CLOCK: BMAL1 transcriptional activator complex. Science 337: 189-194, 2012.

Kadwell, M.; Fernandez, M.; Stanley, H. F.; Baldi, R., Wheeler, J. C.; Rosadio, R. \& Bruford, M. W. Genetic Analysis Reveals the Wild Ancestors of the Llama and the Alpaca. Proc. Biol. Sci. 268: 2575-2584, 2001.

Kumar, S.; Stecher, G. \& Tamura, K. MEGA7: Molecular Evolutionary Genetics Analysis version 7.0 for bigger datasets. Mol. Biol. Evol. 33:1870-1874, 2016.

Llanos, A. J.; Ebensperger, G.; Herrera, E. A.; Reyes, R. V.; Pulgar, V. M.; SerónFerré, M. M.; Díaz, M.; Parer, J. T.; Giussani, D. A.; Moraga, F. A. et al. Fetal and postnatal pulmonary circulation in the Alto Andino. Placenta 32 (Suppl. 2):S100S103, 2011a.

Llanos, A. J.; Ebensperger, G.; Herrera, E. A.; Reyes, R. V.; Moraga, F. A.; Parer, J. T. \& Giussani, D. A. Counterpoint: High Altitude is not for the Birds! J. Appl. Physiol. 111:1515-1518, 2011b.

McGuire, J.; Okamoto, K.; Whitelaw, M. L.; Tanaka, H. \& Poellinger, L. Definition of a dioxin receptor mutant that is a constitutive activator of transcription: delineation of overlapping repression and ligand binding functions within the PAS domain. J. Biol. Chem. 276: 41841-41849, 2001.

Murray, A. A.; Montgomery, H, E.; Feelisch, M.; Grocott, M. \& Martin, D. S. Metabolic adjustment to high-altitude hypoxia: from genetic signals to physiological implications. Biochemical Soc. Transactions, 46: 599-607, 2018. 
Prchal, JT. Production of Erythrocytes, McGraw Hill, New York, 2010.

Price, S. A.; Bininda-Emonds, O. R. P. \& Gittleman, J. L. A. complete phylogeny of the whales, dolphins and even-toed hoofed mammals (Cetartiodactyla). Biol. Rev. 80: 445-473, 2005.

Reisz-Porszasz, S.; Probst, M. R.; Fukunaga, B. N. \& Hankinson, O. Identification of Functional Domains of the Aryl Hydrocarbon Receptor Nuclear Translocator Protein (ARNT). Mol. Cel. Microbiol. 14: 6075-6086, 1994.

Rytkonen, K. T \& Storz, J. F. Evolutionary origins of oxygen sensing in animals. EMBO Rep. 12: 3-4, 2011.

Semenza, G. L.; Agani, F.; Forsythe, J.; Lyer, N.; Jiang, B. H.; Leung, S.; Roe, R.; Wiener, C. \& Yu A. Structural and functional analysis of hypoxia-inducible factor 1. Kidney Int. 51:553-555, 1997.

Semenza, G. I. Regulation of Mammalian O2 Homeostasis by Hypoxia-Inducible Factor 1. Ann. Rev. of Cell and Dev. Biol. 15: 551-578, 1999.

Song, S.; Yao, N.; Yang, M.; Liu, X.; Dong, K.; Zhao, Q.; Pu, Y.; He, X.; Guan, W.; Yang, N.; et al. Exome sequencing reveals genetic differentiation due to highaltitude adaptation of the Tibetan Cashmere goat (Capra hircus) BMC Genomics $17: 122,2016$.

Villafuerte, F. C. \& Corante, N. Chronic Mountain Sickness: Clinical Aspects, Etiology, Management, and Treatment. High Altitude Medicine \& Biology 17, No. 2, 2016.

Wang, G-D.; Fan, R-X.; Zhai, W.; Liu, F.; Wang, L.; Zhong, L.; Wu, H.; Yang, HC.; Wu, S-F.; Zhu, C-L.; et al. Genetic Convergence in the Adaptation of Dogs and Humans to the High-Altitude Environment of the Tibetan Plateau. Gen. Biol. and Evol. 6:2122-2128, 2014.

Wheeler, J. C. South American camelids - past, present and future. J. Camelid Sci. 5:1-24, 2012.

Zhang, W.; Fan, Z.; Han, E.; Hou,; Zhang, L.; Galaverni, M.; Huang, J.; Liu, H.; Silva, P.; Li, P.; et al. Hypoxia adaptations in the grey wolf (Canis lupus chanco) from Qinghai-Tibet Plateau. PLoS Genet. 10: e1004466, 2014. 
Zhou, Y-D.; Barnard, M.; Tian, T.; Li, X.; Ring, H. Z.; Francke, U.; Shelton, J.; Richardson, J.; Russell, D. W.; McKnight, S. L. Molecular characterization of two mammalian bHLH-PAS domain proteins selectively expressed in the central nervous system. Proc. Natl. Acad. Sci. USA 94:713-718, 1997.

Zimmermann, L.; Stephens, A.; Nam, S. Z.; Rau, D.; Kübler, J.; Lozajic, M.; Gabler, F.; Söding, J.; Lupas, A. N. \& Alva, V. A Completely Reimplemented MPI Bioinformatics Toolkit with a New HHpred Server at its Core. J. Mol. Biol. S00222836(17)30587-9, 2017.

FIGURE LEGENDS.

Fig 1. Alignment of Cetartiodactyla HIF1A proteins. Dots indicate identity with the sequence of the top of the figure. Dashes from site 1 to position 62 in short sequences indicate deleted amino acids in the bHLH domain of the HIF1A proteins. Dashes at the end of the proteins indicate unavailable information. Name of the species after accession numbers corresponds to the mention in the material and methods section.

Fig 2. Nucleotide alignment of Cetartiodactyla bHLH domain of HIF1A proteins. Dashes at the beginning of the sequences were introduced for optimal alignment. Asterisk at the bottom of sequences between position sites 20-29 indicate the Thymine rich stretch of the sequences. Stop codons are in bold letters. Name of the species after accession numbers corresponds to that mention in the material and methods section.

Fig 3. Phylogenetic trees based on selected nucleotide bHLH domain of Cetartiodactyla HIF1A sequences. The numbers shown on the interior nodes are 
bioRxiv preprint doi: https//doi org/10.1101/386987; this version posted August 7, 2018. The copyright holder for this preprint (which was not certified by peer review) is the author/funder, who has granted bioRxiv a license to display the preprint in perpetuity. It is made available under aCC-BY-NC-ND 4.0 International license.

bootstrap probabilities in percent. The parameters pairwise deletion and p-distance model were used. 
Fig 1. Alignment of Cetartiodactyla HIF1A proteins. Dots indicate identity with the sequence of the top of the figure. Dashes from site 1 to position 62 in short sequences indicate deleted amino acids in the bHLH domain of the HIF1A proteins. Dashes at the end of the proteins indicate unavailable information. Name of the species after accession numbers corresponds to the mention in the material and methods section. 
Fig 2. Nucleotide alignment of Cetartiodactyla bHLH domain of HIF1A proteins.

Dashes at the beginning of the sequences were introduced for optimal alignment.

Asterisk at the bottom of sequences between position sites 20-29 indicate the

Thymine rich stretch of the sequences. Stop codons are in bold letters. Name of

the species after accession numbers corresponds to that mention in the material and methods section. 
Fig 3. Phylogenetic trees based on selected nucleotide bHLH domain of

Cetartiodactyla HIF1A sequences. The numbers shown on the interior nodes are

bootstrap probabilities in percent. The parameters pairwise deletion and p-distance

model were used. 
NP_001116596.1_Susc_L XP_007471761.1_Live_S XP_007193021.1_Baac_s XP_019778656.1_Tutr_s XP_015105562._-Vhca_s XP-014415631.1_Cafo XP_01097431.._Care_s XP XP-017909034. Cahi$\mathrm{XP}^{-} 020752077$. ${ }^{-}$Odvi XP-010845948.1_Bibis

XP NP_001116596.1_Susc_I

XP_007193021.1_Baac_S

XP_019778656.1_Tutr_S

XP-015105262.1_Vipa-

XP_014415631.1_Cafes

XP-010974976.1_Cadr-

NP-001272657.1_Cahi

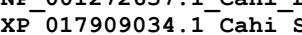

$\mathrm{XP}^{-020752077.1^{-} \text {Odvi }}$

$\mathrm{XP} 010845948.1^{-} \mathrm{Bibi}^{-}$

NP 001116596.1 Susc I XP-007471761.1_Live XP 007193021.1 Baac XP_019778656.1 Tutr XP_007109956.2_Phca_ XP 015105262.1 Vipa XP_014415631.1 Cafe XP_010974976.1 Cadr NP_001272657.1 Cahi XP_017909034.1_Cahi_ XP_020752077.1_Odvi_S XP_010845948.1_Bibi_S

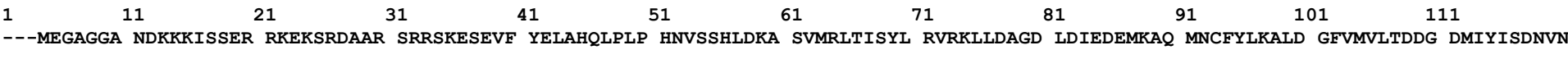

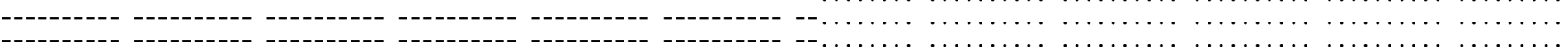
-

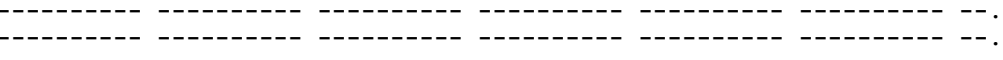

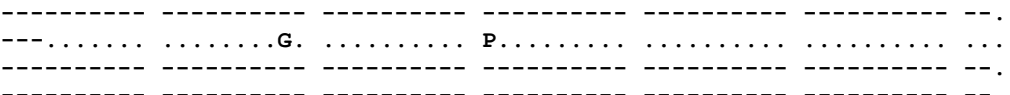

$\begin{array}{lllllllllll}131 & 141 & 151 & 161 & 171 & 181 & 191 & 201 & 211 & 221 & 231\end{array}$

KYMGLTQFEL TGHSVFDFTH PCDHEEMREM LTHRNGLVKK GKEQNTQRSF FLRMKCTLTS RGRTMNIKSA TWKVLHCTGH IHVYDTNNNQ SQCGYKKPPM TCLVLICEPI PHPSNIEIPL

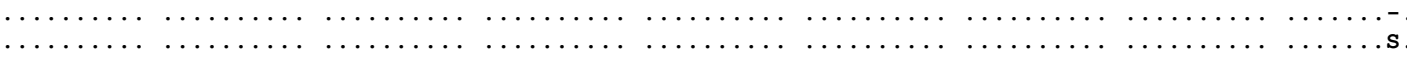

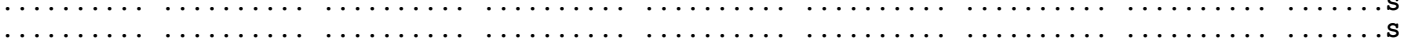

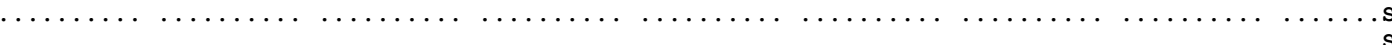

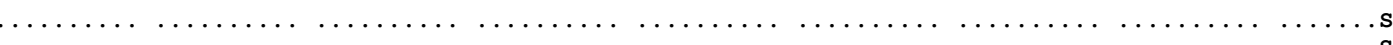

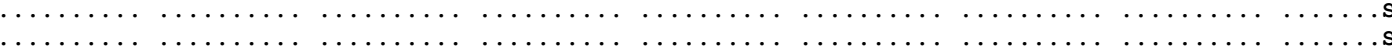

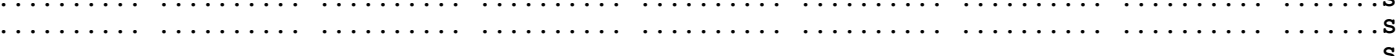
251
261
271
281
291
301
311
321
331
341
351

241

DSKTFLSRHS LDMKFSYCDE RITELMGYEP EELLGRSIYE YYHALDSDHL TKTHHDMFTK GQVTTGQYRM LAKRGGYVWV ETQATVIYNT KNSQPQCIVC VNYVVSGIIQ HDLIFSLQQT

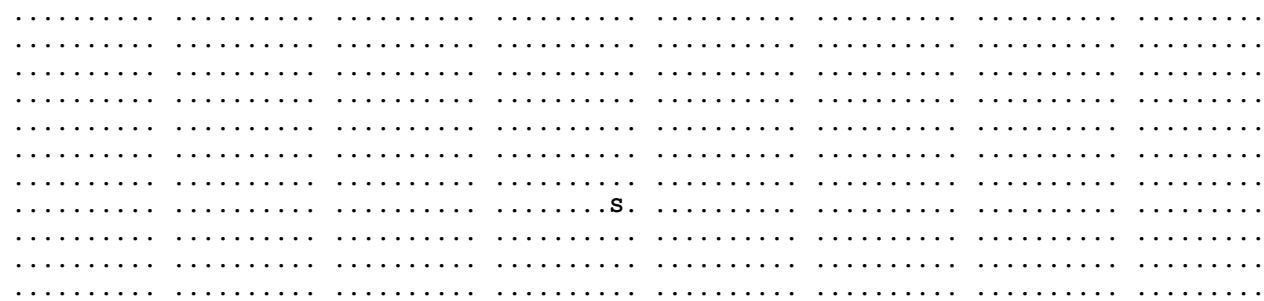

$\begin{array}{lllllllll}361 & 371 & 381 & 391 & 401 & 411 & 421 & 431 & 441\end{array}$

451

461

471

NP_001116596.1_Susc_I

XP_007471761.1_Live_S

XP_007193021.1_Baac-

XP_019778656.1_Tutr_S

XP_007109956.2_Phca_

XP_015105262.1_Vipa_s

XP_014415631.1_Cafe_S

XP_010974976.1_Cadr_S

NP_001272657.1_Cahi_

XP_017909034.1_Cahi_s

XP_020752077.1_Odvi_S

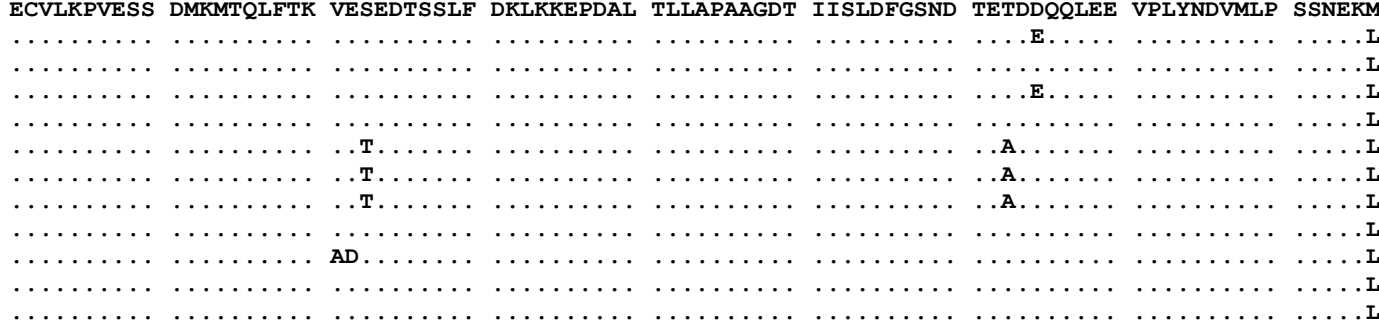

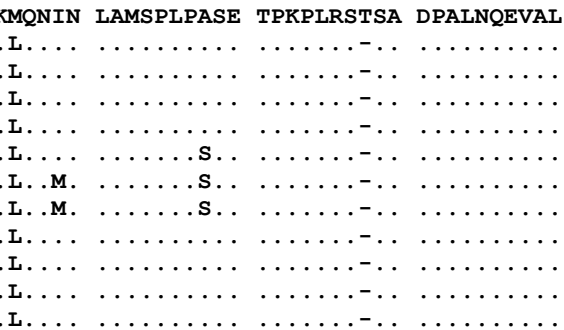

Fig 1. Alignment of Cetartiodactyla HIF1A proteins. Dots indicate identity with the sequence of the top of the figure. Dashes from site 1 to position 62 in short sequences indicate deleted amino acids in the bHLH domain of the HIF1A proteins. Dashes at the end of the proteins indicate unavailable information. Name of the species after accession numbers corresponds to the mention in the material and methods section. 
XM_022570429.1_Dele_S XM-007109894.2_Phca_S XM_019923097.1_Tutr_S XM_018053545.1_Cahi_S XM-010847647.1-Bibi_S XM-020896418.1_Odvi_S ABRR02138382.1_Vipa_S JGVD01013070.1_Cadr_S AM 010847646.1 Bibi_S XM_007471699.1_Live_S XM 015097105.1_Ovar_L XM_010847645.1_Bibi_L DQ838048.1 Bogr L

XM 005960085.1 Paho L

XM_022570429.1_Dele_S XM-007109894. XM-019923097.2_Phca_S XM-018053545.1 CatrXM-010847647. XM-020896418.1-Odvi-S ABRR02138382.1_-Vipi-S ABRR02138382.1_Vipa_S AGVR01032341._Cadr-S AGVR01032341.1_Cafe_S XM 007471699 . Bibi_S XM_007471699.1_Live_S XM 010847645.1 Bibi_L DQ838048.1 Bogr L XM_005960085.1_Paho_L

XM 022570429.1 Dele S XM 007109894.2 Phca S XM 019923097.1 Tutr S $\mathrm{XM}^{-} 018053545.1^{-} \mathrm{Cahi}^{-} \mathrm{S}$ XM 010847647.1 Bibi S XM-020896418.1 Odvi S ABRR02138382.1 Vipa S JDVD01013070.1 $\mathrm{Cadr}^{-} \mathrm{S}$ AGVR01032341.1 Cafe XM_010847646.1 Bibi ${ }^{-}$ XM_007471699.1_Live S XM_015097105.1_Ovar_I XM_010847645.1_Bibi_I

DQ $\overline{8} 38048.1$ Bogr $\bar{r}$ L
XM_005960085.1_Paho_L

1 20 (1) ATC TTC 作

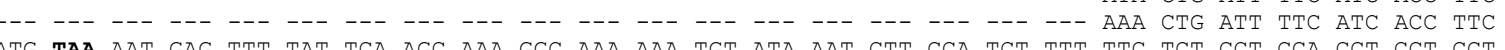
ATG TAA AAT GAG TIT TAT TCA AGC AAA GGC AAA AAA TGT ATA AAT CTI CCA TCT TTT TTC TCT CCT CCA CCT CCT CCT ATG TA AAT GAG TIT TAT TCA AGC AAR GGC XAC XAR ATG TAA AAT GAG TIT TAT TCA AGC AAA GGC AAC AAA TGI ATA AAT TIT CCA ICT TIT TIC TCI CCI CCA CCI CCI CCT CG (1) --.

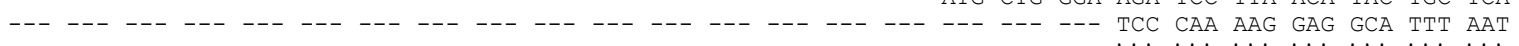

40

50

TTC ATC TAA TTT AGg ATA AGT TCT GAA CGT CGA AAA GAG AAG TCT AGA GAT GCA GCC AGA TCT CGA CGA AGT AAA GAG TTC ATC TAA TTT AGG ATA AGT TCT GAA CGT CGA AAA GAG AAG TCT AGA GAT GCA GCC AGA TCT CGA CGA AGT AAA GAG TTC ATC TAA TTT AGG ATA AGT TCT GAA CGT CGA AAA GAG AAG TCT AGA GAT GCA GCC AGA TCT CGA CGA AGT AAA GAG TTC ATC TAA TTT AGg ATA AGT TCT GAA CGT CGA AAA GAg AAg TCT AGA GAT GCA GCC AGA TCT CGT CGA AGT AAA GAG TTC ATC TAA CTT AGg ATA AGT TCT GAA CGT CGA AAA GAg AAg TCT AGA GAT GCA GCC AGA TCT CGT CGA AGT AAA GAG TTT TTC TTA AAT AGC ATA AGT TCT GAA CGT CGA AAA GAG AAA TCT AGA GAT GCA GCC AGA TCT CGA CGA AGT AAA GAG TTT TTG TTA AAT AGG ATA AGT TCT GAA CGT CGA AAA GAG AAA TCT AGA GAT GCA GCC AGA TCT CGA CGA AGT AAA GAG TTT TTG TTA AAT AGG ATA AGT TCT GAA CGT CGA AAA GAG AAA TCT AGA GAT GCA GCC AGA TCT CGA CGA AGT AAA GAG TGT CAA CTC TTG AGG ATA AGT TCT GAA CGT CGA AAA GAG AAG TCT AGA GAT GCA GCC AGA TCT CGT CGA AGT AAA GAG GTG CTC AAT AAA TGG ATA ACT TCT GAA CGT CGA AAA GAG AAG TCT AGA GAT GCA GCC AGA TCT CGA CGA AGT AAA GAG GTG CTT AGT AAA TGG ATA AGT TCT GAA CGT CGA AAA GAG AAG TCT AGA GAT GCA GCC AGA TCT CGT CGA AGT AAA GAG GTG CTT AGT AAA TGG ATA AGT TCT GAA CGT CGA AAA GAG AAG TCT AGA GAT GCA GCC AGA TCT CGT CGA AGT AAA GAG GTG CTT AGT AAA TGG ATA AGT TCT GAA CGT CGA AAA GAG AAG TCT AGA GAT GCA GCC AGA TCT CGT CGA AGT AAA GAG CTT TTT TCC ACC AAg ATA AGT TCT GAA CGT CGA AAA GAg AAA TCT AGA GAT GCA GCC AGA TCT CGT CGA AGT AAA GAG 60 70

TCT GAA GTT TTT TAT GAg CTT GCT CAT CAG TTG CCA CTT CCC CAT AAT GTG AGC TCA CAT CTT GAT AAg GCT TCT GTT TCT GAA GTT TTT TAT GAG CTT GCT CAT CAG TTG CCA CTT CCC CAT AAT GTG AGC TCA CAT CTT GAT AAG GCT TCT GTT TCT GAA GTT TTT TAT GAG CTT GCT CAT CAG TTG CCA CTT CCC CAT AAT GTG AGC TCA CAT CTT GAT AAG GCT TCT GTT TCT GAA GTT TTT TAT GAG CTT GCT CAT CAG TTG CCG CTC CCC CAT AAT GTA AGC TCG CAT CTT GAT AAG GCT TCT GTT TCT GAA GTT TTT TAT GAG CTT GCT CAT CAG TTG CCA CTC CCC CAT AAT GTA AGC TCG CAT CTT GAT AAG GCT TCT GTT TCT GAA GTT TTT TAT GAG CTT GCT CAT CAG TTG CCA CTC CCT CAT AAT GTA AGC TCG CAT CTT GAT AAG GCT TCT GTT TCT GAA GTT TTT TAT GAG CTT GCT CAT CAG CTG CCA CTT CCC CAT AAT GTG AGC TCG CAT CTT GAT AAG GCT TCT GTT TCI GAA GTT TTT TAT GAG CTT GCT CAT CAG CTG CCA CTT CCC CAT AAT GTG AGC TCG CAT CTT GAT AAG GCT TCT GTT ICI GAA GTT TTT TAT GAG CTT GCT CAT CAG CTG CCA CTT CCC CAT AAT GTG AGC TCG CAT CTT GAT AAG GCT TCT GTT ICT GAA GTT TTT TAT GAG CTT GCT CAT CAG TTG CCA CTC CCC CAT AAT GTA AGC TCG CAT CTT GAT AAG GCT TCT GTT 1CI GAA GTT TTT TAT GAG CTT GCT CAT CAG TTG CCA CTT CCC CAT AAT GTG AGC TCA CAT CTT GAT AAG GCT TCT GTT TCI GAA GTT TTT TAT GAG CTT GCT CAT CAG TTG CCA CTC CCC CAT AAT GTA AGC TCG CAT CTT GAT AAG GCT TCT GTT TCI GAA GTT TTT TAT GAG CTI GCT CAT CAG TTG CCA CTC CCC CAT AAT GTA AGC TCG CAT CTT GAT AAG GCT TCT GIT TCT GAA GTT TTT TAT GAG CTT GCT CAT CAG TTG CCA CTC CCC CAT AAT GTA AGC TCG CAT CTT GAT AAG GCT TCT GTT
TCT GAA GTT TTT TAT GAG CTT GCT CAT CAG TTG CCA CTC CCC CAT AAT GTA AGC TCG CAT CTT GAT AAg GCT TCT GTT

Fig 2. Nucleotide alignment of Cetartiodactyla bHLH domain of HIF1A proteins. Dashes at the beginning of the sequences were introduced for optimal alignment. Asterisk at the bottom of sequences between position sites 20-29 indicate the Thymine rich stretch of the sequences. Stop codons are in bold letters. Name of the species after accession numbers corresponds to that mention in the material and methods section. 


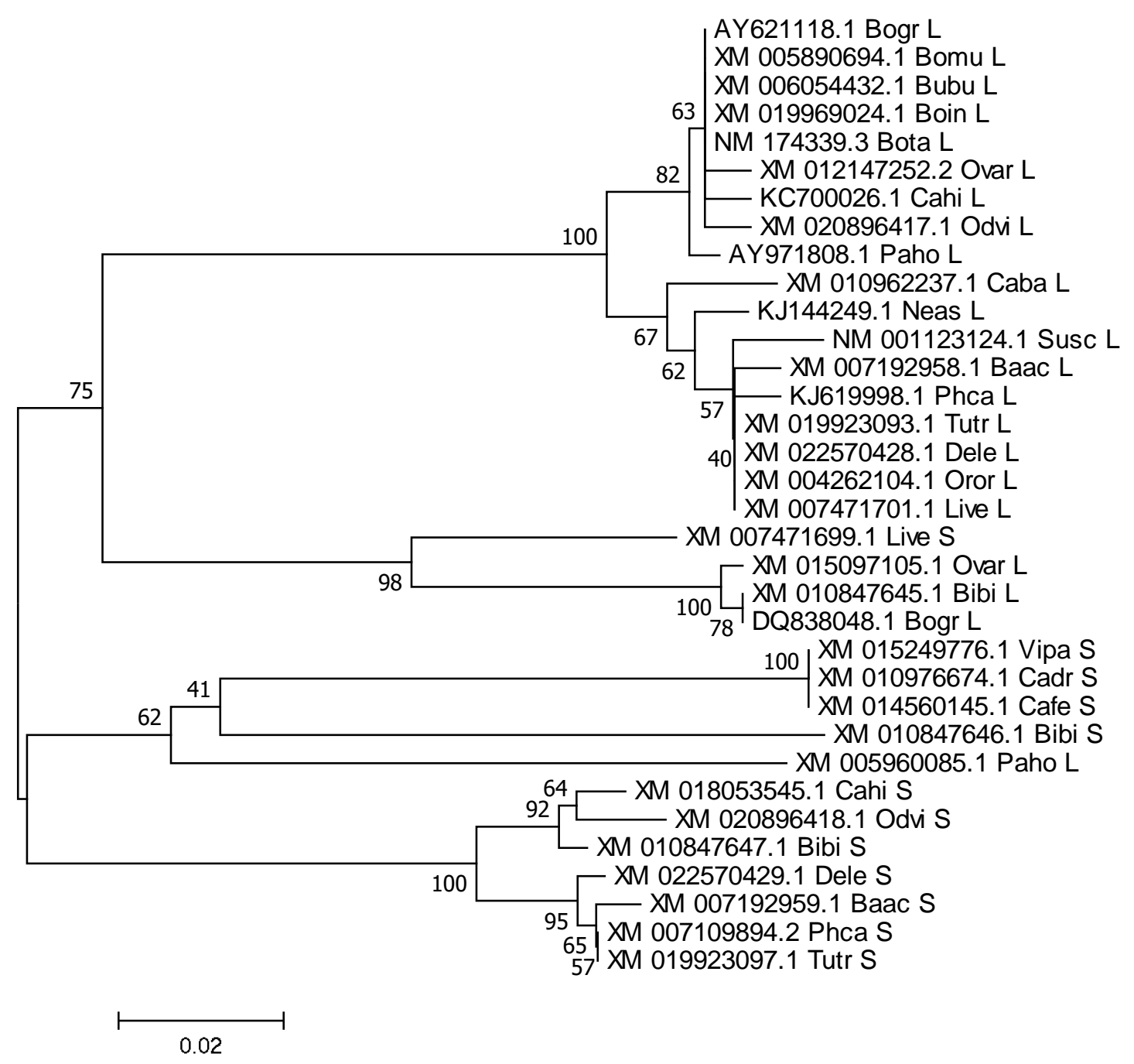

Fig 3. Phylogenetic trees based on selected nucleotide bHLH domain of Cetartiodactyla HIF1A sequences. The numbers shown on the interior nodes are bootstrap probabilities in percent. The parameters pairwise deletion and p-distance model were used. 


\section{Supplementary material A}

NP_001116596.1_SusC_L XP_-007471763.1_Live_ XP_007471762.1_Live_XP 007193020.1 Baac $\mathrm{XP}_{-} 007193021.1_{\text {Baac }} \mathrm{S}$ AHN 85600.1 Neas L

XP_00426215̄2.1 Oror

XP-019778656.1 TutrS

AIB53793.1 Dele L

AIB53792.1 Phca L

XP_007109955.2_Phca_L

XP_007109956.2_Phca_S

EPȲ80386.1_Café L

XP_015105262.1_Vipa_S

XP_010960539.1 Caba

XP_014415631.1_Cafe_S

XP_010974976.1_Cadr

XP_005960147.1_Paho_

NP_001272657.1_Cahi_I

AEL79603.1_Paho_-

AAX89137.1_Paho-

AGM38929.1 Cahi- L

XP_014964363.1_Ovar_L

XP_017909034.1_Cahi_

AEW̄10558.1_Cahi_L

XP_012002642.1_Ovar_I

XP_020752076.1_Odvi_I

XP_020752077.1_Odvi_S

Q0 $\overline{P G G 7}$.1_Bogr_ $\overline{\mathrm{L}}$

ABH06560.1_Bogr_L

ABH06559.1 Bogr_L

Q9X̄TA5.1_Bota_ $\overline{\mathrm{I}}$

XP_010845947.1.Bibi_I

NP 776764.2 Bota_L

XP_010845948.1_Bibi_S

11

$21 \quad 31$ 41 51 81 101 111

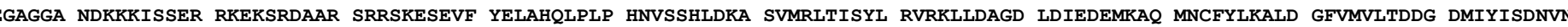

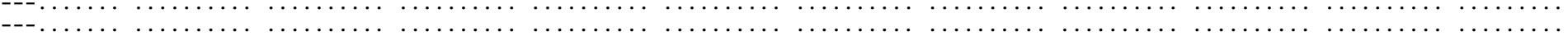
$--\ldots \ldots+\ldots \ldots+\cdots$

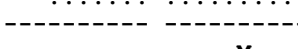
$--\ldots \ldots \ldots, \ldots \ldots$ M. 
NP_001116596.1_Susc_I XP_00747163.1_Live_ XP_007471762.1Live_ XE-007193020.1_XP_007193021_Bac_ $X \mathrm{~N} \times 5600.11$

AHN85600.1 Neas

XP_004262152.1_Oror_ XIB53793 .

AIB53792.1-

XP_007109955.2_Phca

XP_007109955.2_Phca_L

EPY 80386.1 Cafe_L

XP_0151052 б2.1_Vipa_S

XP_010960539.1_Caba_L

XP_014415631.1_Cafe_S

XP-010974976. Cadr

XP-005960147. Paho

NP $001272657.1^{-}{ }^{-} a h i^{-}$

AĒ̄79603.1 Pahō I

AAX89137.1 Paho-

AGM38929.1 Cahi I

XP_01496436̄3.1_Ovar_L

XP-017909034.1_Cahi_

AEพ̄ 10558.1_Cahi_L

XP_012002642.1_Ovar_L

XP_020752076.1_Odvi I

XP_020752077.1 Odvi

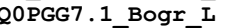

ABH0 6560.1 Bogr

ABH0 6559.1_Bogr_

XP_005890756.1 Bomu_L

Q9XTA5.1_Bota_

XP_010845947.1 Bibi

NP 776764.2 Bota 1

EL $\bar{R} 60049.1$ Bomu $\overline{\mathrm{L}}$

XP_010845948.1_Bibi_S

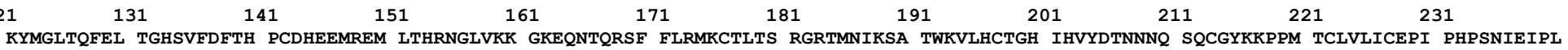

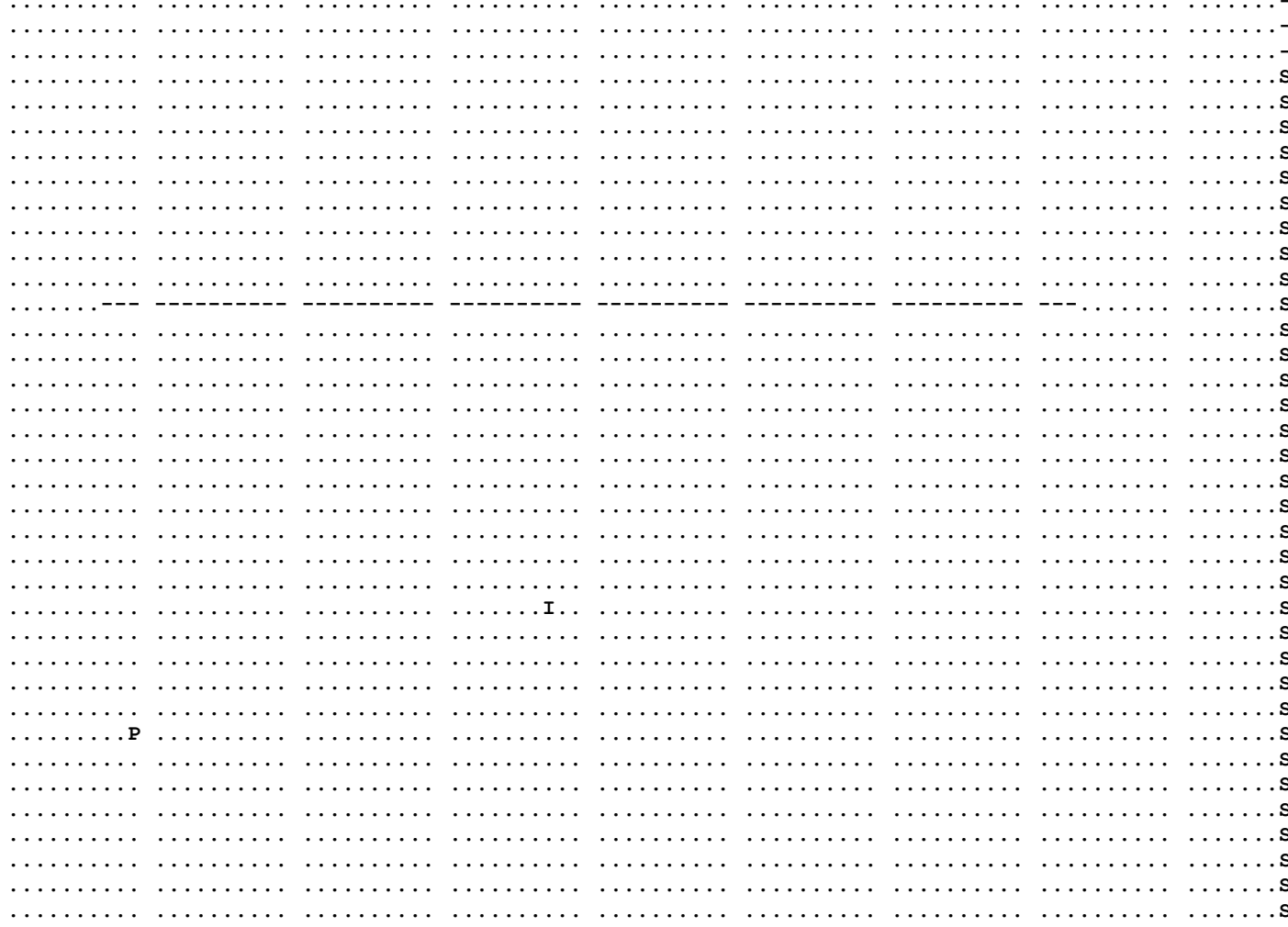

SOCGYKKPPM TCLVITCEPI PHPSNIEIPL

. $\mathbf{E}$

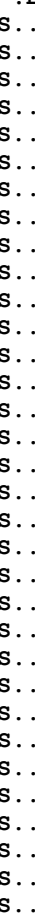


NP_001116596.1_Susc_L XP_007471763.1_Live_I XP_007471762.1_Live_ XP-007193020. _ive_ XP_-007193021_Baac_ AHN 85600.11 AHN85600.1 Neas

XP_004262152.1_Oror_AIB53793 1 . AIB53792.1-Phe_-

AIB53792.1 PhCa L

XP_007109955.2_Phca_L

EPY80386.1

EPY 00386.1 Cafe $L$

XP_015105262.1_Vipa_S

XP_014415631.1_Cafe-s

XP-010974976.1_Cadr-

$X P$-005960147.

NP $001272657.1^{-} \mathrm{Cahi}$

AĒ̄79603.1 Pahō L

AAX89137.1 Paho-

AGM38929.1 Cahi I

XP_014964363.1_Ovar_L AEW̄10558.1 Cahí $\mathrm{L}$

XP $0120026 \overline{4} 2.1$ Ovar

XP_020752076.1_Odvi I

XP_020752077.1 Odvi S

Q0PGG7.1 Bogr L

ABH0 6560.1 Bogr

ABH06559.1 Bogr

XP_005890756.1 Bomu_L

Q9XTA5.1_Bota_

XP_010845947.1. Bibi

NP-776764.2_Bota_L

ELR60049.1 Bomu $\overline{\mathrm{L}}$

XP_010845948.1_Bibi_S

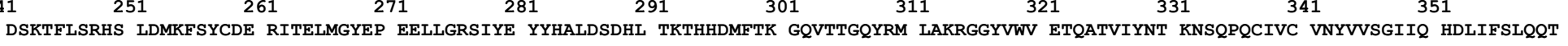

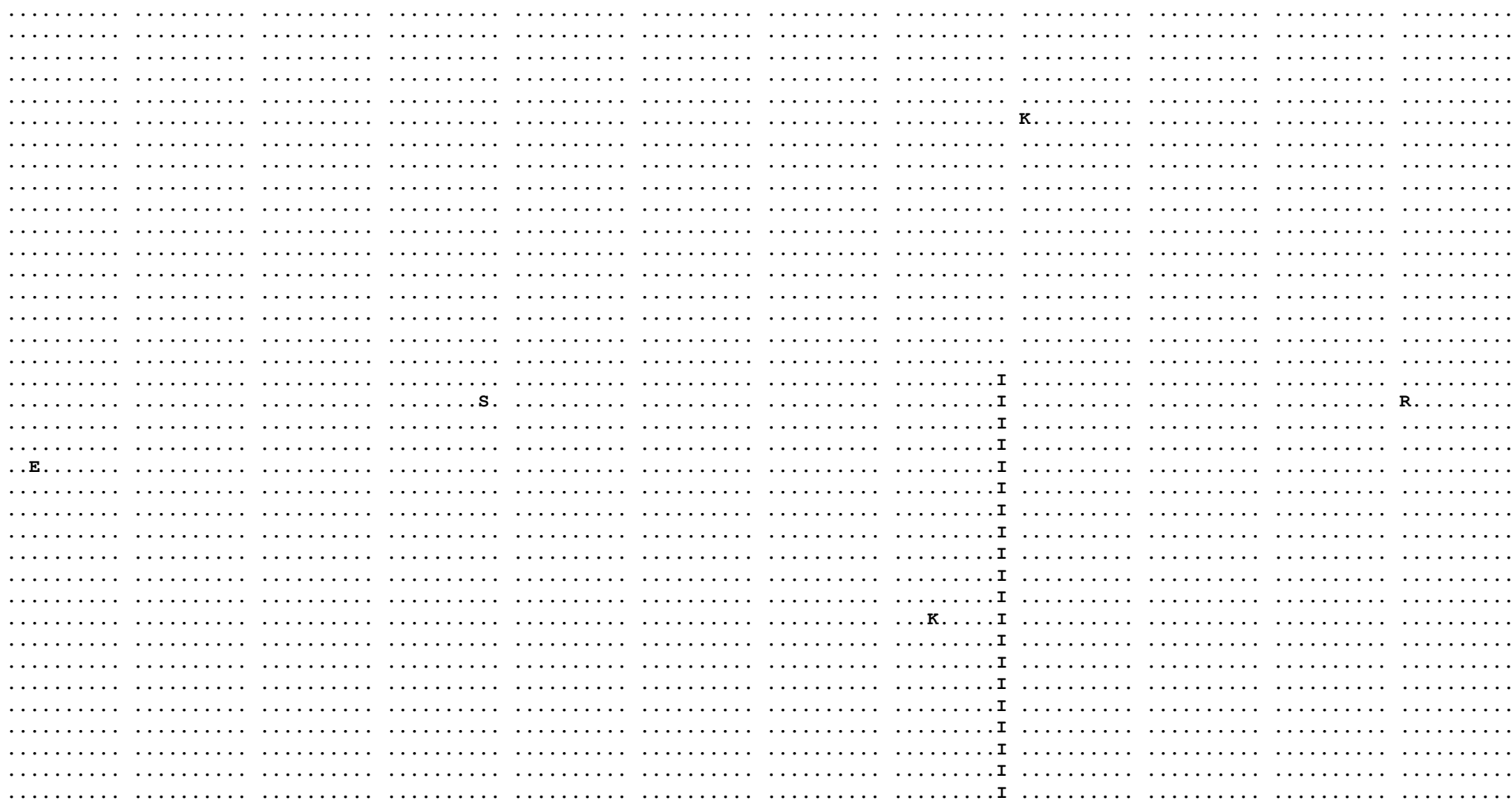




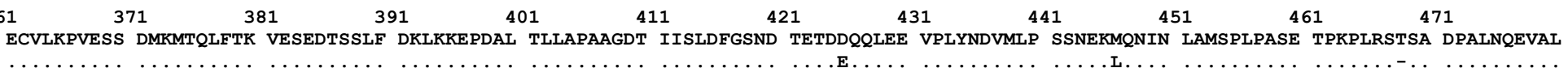
NP_001116596.1_Susc_I XP_007471763.1_Live_ XP_007471762.1_Live_ XP-007193020.1XP_007193020.1_Baac_ $X{ }_{1}=07193021.1$ Baac_ AR 560 . -Neas

XP-019778656__oror_ AIB 53793.1 Delé $L$ AIB53792.1_Dele_-

XP 007109955

XP_00710995.2_Phca

EPY 80386.1 Caf

XP $0151052 \overline{6} 2 \overline{\mathrm{V}}$ ipa

XP_015105262.1-Vipa_S

XP-014415631.

$X P-010974976$. Cadr-S

$X P-005960147.1$ Paho

NP-001272657.1 Cahi

AEẼ79603.1 Paho

AEX 89137.1-Paho-

AGM38929.1 Cahi ${ }^{-}$

XP_014964363.1_Ovar_L

AEW̄10558.1 Cahi $\bar{L}$

XP_012002642.1_Ovar_L

XP 020752076.1 Odvi I

XP-020752077.1-Odvi ${ }^{-}$S

Q0 PGG7.1 Bogr $\overline{\mathrm{L}}$

ABH06560.1 Bogr

ABH06559.1 Bogr L

XP_005890756.1 Bomu_L

Q9XTA5.1_Bota_

XP_010845947.1 Bibi

NP 776764 .2 Bota_L

EL $\bar{R} 60049.1$ B Bomu $\bar{L}$

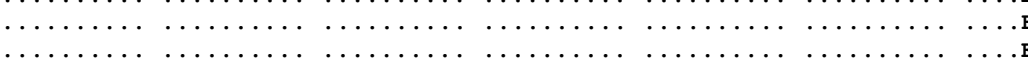

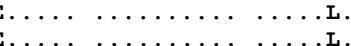

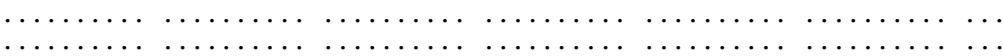

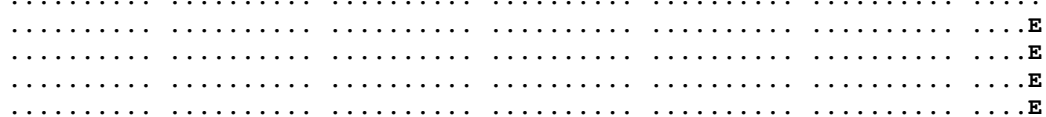


$\begin{array}{lllllllllll}481 & 491 & 501 & 511 & 521 & 531 & 541 & 551 & 561 & 571 & 581\end{array}$ NP_001116596.1_Susc_L 71763.1_Live_I XP_007471762.1 XP-007193020 - Baac$\mathrm{XP}^{-} 007193021$. Baac- $^{-}$ AHN̄ 85600.1 Neas $\bar{L}_{\text {L }}$

XP $0042621 \overline{5} 2.1$

XP_019778656__-Oror_XID53793 1 . AIB53792.1-

XP 007109955 Ca

XP_007109955.2_Phca_I

EPY 80386.1 Cafe_L

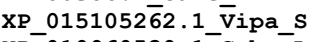

XP-010960539.

$X P^{-} 014415631.1$ Cafe

XP 010974976.1 Cadr-

XP-005960147.1 Paho

NP 001272657. Cahi $^{-}$

AĒ̄79603.1 Pahō I

AAX89137.1 Paho-

AGM38929.1 Cahi I

XP_01496436̄3.1_-ovar_L

XP_017909034.1-Cahi_

AEW̄1 0558 .1_Cahí_L

XP_012002642.1_Ovar_L

XP_020752076.1 Odvi

XP_020752077.1 Odvi S

Q0PGG7.1 Bogr I

ABH0 6560.1 Bog $r$

ABH06559.1 Bogr I

XP_005890756.1_Bomu_L

Q9XTA5.1_Bota_

XP_010845947.1_Bibi

NP_776764.2_Bota_L

ELT $\bar{R} 60049.1 \bar{B}$ Bomu $\bar{L}$

XP_010845948.1_Bibi_S

KLEPNPESLE LSFTMPQIQD QPASPSDGST RQSSPEPNSP SEYCFDVDSD MVNEFKLELV EKLFAEDTEA KNPFSTQDTD LDLEMLAPYI PMDDDFQLRS FDQLSPLESS STSPQSTSTI

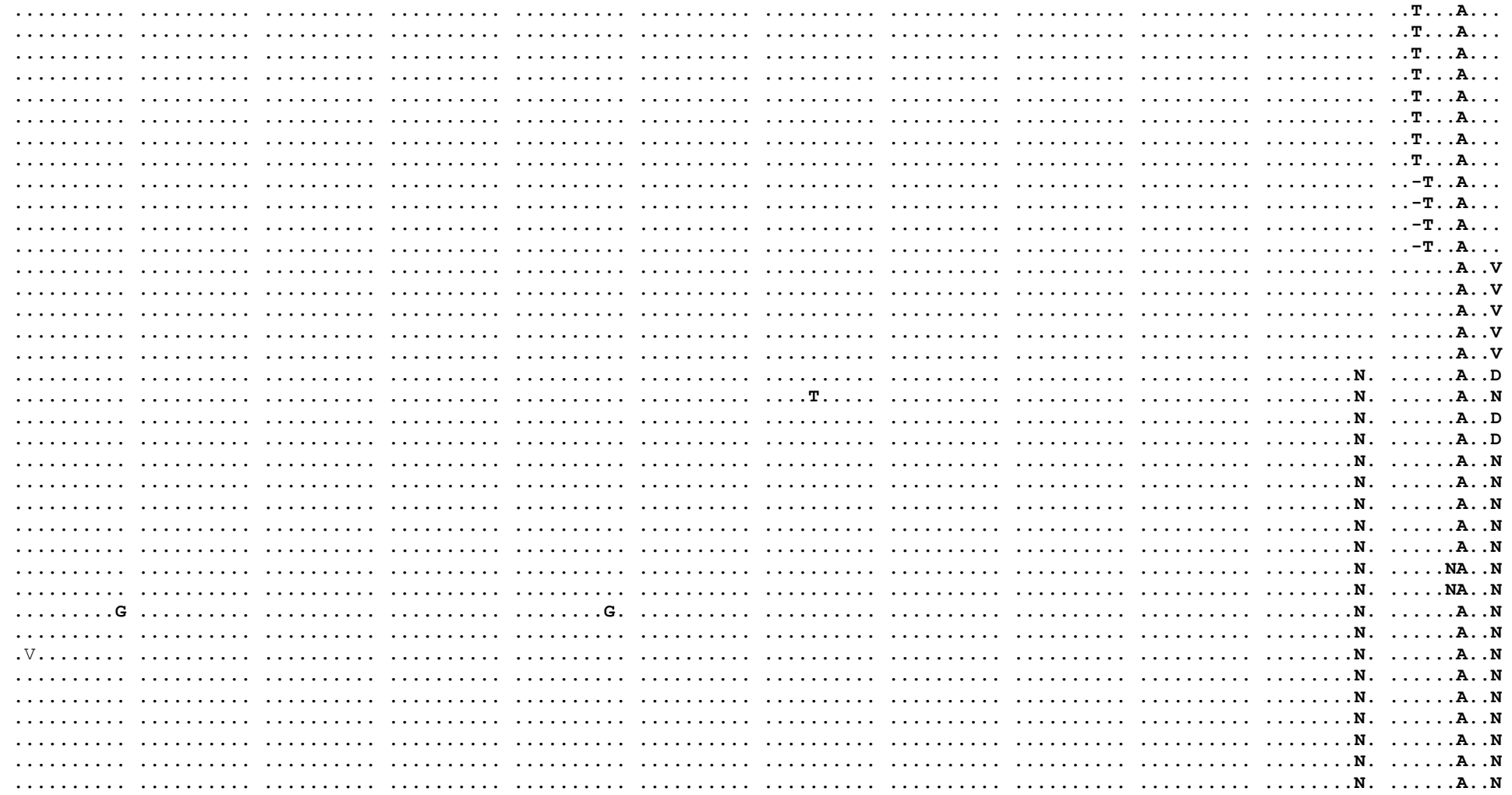


NP_001116596.1_Susc_I XP-007471763.1 Live XP 007471762.1 Live $X P^{-} 007471761$ - LiveXP 007193020.1_Baac XP_007193021.1 BaacAHN85600.1 Neas _

XP_004262152.1_Oror_I XP_019778656.1_Tutr_S AIB53793.1 Dele

AIB53792.1_Phca_L

XP_007109955.2_Phca_I

XP_007109956.2_Phca-S

EPY80386.1_Cafe_I

XP_015105262.1_Vipa_s

-0109639. Caba

XP-010974976.1 Cadr-

XP 005960147.1 Paho-

NP $001272657.1^{-} \mathrm{Cahi}^{-}$

AEİ79603.1_Paho_I

AAX89137.1_Paho_I

AGM38929.1-Cahi-L

XP_014964363.1 D-Ovar_L

XP_017909034.1_Cahi

AEW10558.1 Cahi L

XP_012002642.1_Ovar

XP_020752076.1_Odvi_-

OOPGG7.1 Bogr $\overline{\mathrm{L}}$

ABH0 6560.1 Bogr

ABH06559.1 BOgr_L

XP_005890756.1_Bomu_L

Q9XTA5.1_Bota_I

XP_010845947.1.Bibi_L

NP_776764.2_Bota_L

ELR 60049.1 Bomu_ $\overline{\mathrm{L}}$
XP $010845948.1 \bar{B}$ ibi

$\begin{array}{llllllllllll}601 & 611 & 621 & 631 & 641 & 651 & 661 & 671 & 681 & 691 & 701 & 711\end{array}$

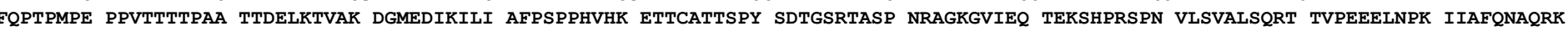
Q.Q. A.I.N.TT.

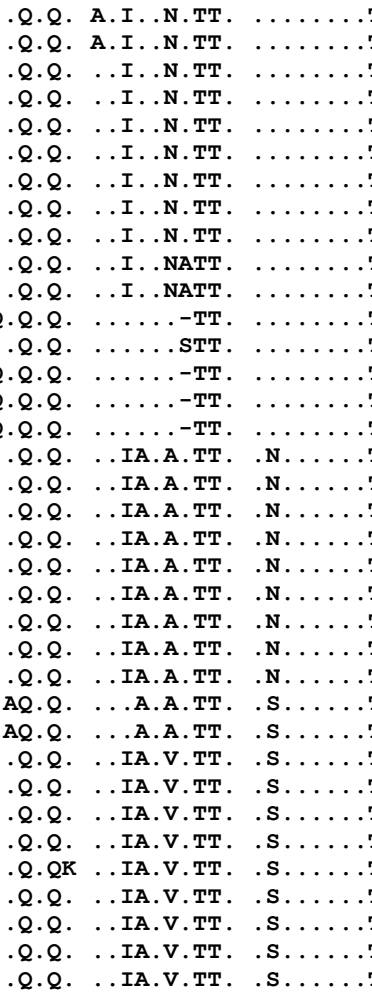

T.
T.
T.
T.
T.
T.
T.
T.
T.
T.
T.
T.
T.
T.
T.
T.
T.
T.
T.
T.
T.
T.
T.
T.
T.
T.
T.
T.
T.
T.
T.
T.
T.
T.


72

731

741

751

761

$771 \quad 781$

791

801

811

821

NP_001116596.1_Susc_L XP_007471763.1_Live_ XP_00747172.1_Live_

XP-007193020__

XP-007193021.

XYN 85600.11 Baac_

XP 004262152 -

XP_004262152.1_Oror_

AIB53793 1 Del-

AIB53792.1-Dele_

XP 007109955 - $\mathrm{L}$

XP-007109956.2-Phca

EPY 80386.1 Cafe_L

XP_0151052 62.1 - $\overline{\text { Vipa_S }}$ XP-010960539.1 CabaLL

XP-014415631.

$X P$-010974976.1 Cadr-

XP-005960147.1 Paho

NP-001272657.1 Cahi

AE'̄79603.1 Paho I

AAX89137.1 Paho-

AGM38929.1 Cahi $^{-}$

XP_014964363.1_OVvar_L

AEW̄10558.1 Cah' $\bar{i}$ L

XP_012002642.1 Ōvar

XP 020752076.1 Odvi I

XP_020752077.1 Odvi

Q0PGG7.1 Bogr I

ABH06560.1 Bogr

(1)

XP_005890756.1_Bomu_L

Q9XTA5.1_Bota_

XP_010845947. 1 Bibi_L

NP_776764.2_Bota_L

ELR60049.1_Bomu_ $\bar{L}$

XP_010845948.1_Bibi_S

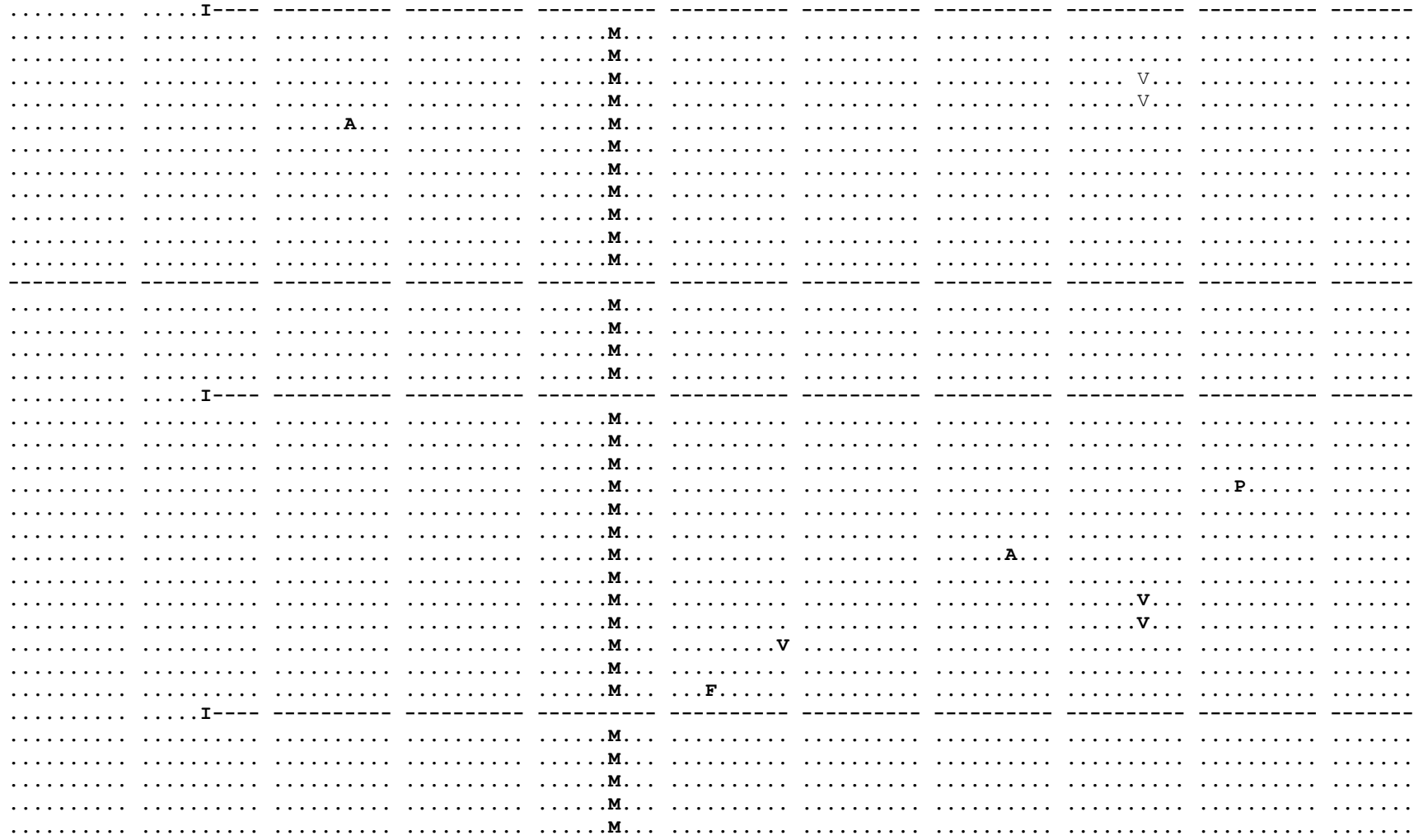


Supplementary material B

XM 007192959.1 Baac S $\mathrm{XM}^{-}$022570429.1 Dele-S XM-007109894.2 PhcaXM_019923097.1_Tutr_S XM_018053545.1_Cahi_S XM 010847647.1 Bibi S XM 020896418.1 Odvi AB $\bar{R}$ R02138382.1 Vipa JDVD01013070.1 ${ }^{-} \mathrm{Cadr}^{-} \mathrm{S}$ AGVR01032341.1 CafeXM 010847646.1 BibiXM_007471699.1_Live_S XM_015097105.1_Ovar_I XM 010847645.1 Bibi I DQ838048.1_Bogr_L

XM 005960085.1 Paho L AY $\overline{9} 71808.1$ Pahō I

XM_01214725 2.2_Ovar_I XM_020896417.1_Odvi_I KC̄̄00026.1_Cahī_L NM $174339 . \overline{3}$ Botà L

XM_019969024.1 Boin I XM_006054432.1_Bubu_I AY 621118.1 Bogr I

XM $0058906 \overline{9} 4.1$ B Bomu I XM-010962237.1_Caba_I NM_001123124.1_Susc_I KJ1̄44249.1_Neas__ KJ619998.1 ${ }^{-}$Phca ${ }^{-}$

XM_019923093.1_Tutr_ XM 022570428.1 Dele XM 004262104.1-Oror XM-007471701.1-Oror XM_007192958.1_Baac_L
1210

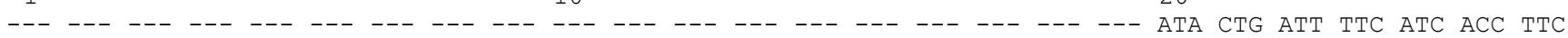
(1) - ATA CTG ATT TTC ATC ACC TTC ATC ACC TTC 等 作 ATG TAA AAT GAG TTT TAT TCA AGC AAA GGC AAC AAA TGT ATA AAT TTT CCA TCT TTT TTC TCT CCT CCA CCT CCT CCT ATG TAA AAT GAG TTT TAT TCA AGC AAA GGC AAC AAA TGT ATA AAT TTT CCA TCT TTT TTC TCT CCT CCA CCT CCT CCT

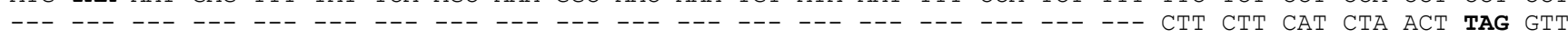

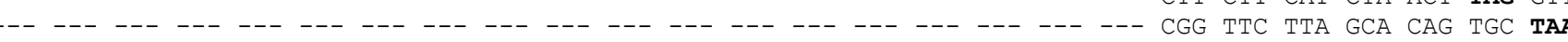
- - - - - ( -.- - - - - - - - - - - - - - - - - - - - - - - - - - - - - - - - - - - - - - - - - - - - - - - - - - - - - - - - - - - - (1) - - - - - - - - - - - - - -

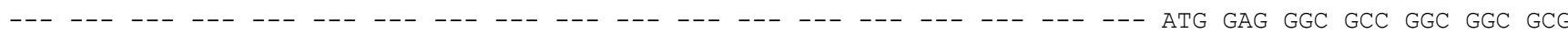
- - - - - - - - - - - - - - - - - - - - - - - - - - - - - - - - -

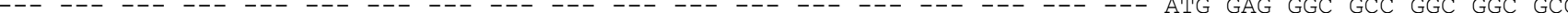
-

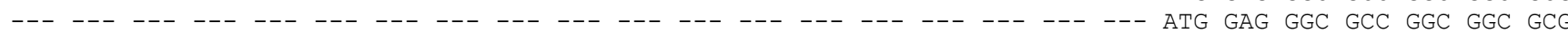


30

M 007192959.1_Baac_S XM 022570429.1 Dele S XM 007109894.2 Phca XM 019923097.1-Tutr_S XM-018053545.1 Cahi-s XM-010847647.1_BibiXM_020896418.1_Odvi_S ABRR02138382.1-Vipa S JDVD01013070.1 Cadr AGVR01032341.1_Cafe-S XM 010847646.1 Bibi XM-007471699.1-LiveXM-015097105.1_ovarXM-015097105.1_ovar_DQ838048.1_Bogr_L XM_005960085.1 Paho L AY971808.1 Paho I XM 012147252.2_Ovar_I XM 020896417.1-Odvi KC̄̄00026.1_Cahìi_L NM_174339.3_Bota_L

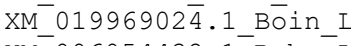
XM_006054432.1_Bubu_I AY621118.1_Bogr I XM $0058906 \overline{9} 4.1$ Bomu I XM 010962237.1 Caba_L NM 001123124.1_Susc_ KJ̄̄44249.1_Neas I KJ619998.1-PhCaXM 019923093.1_Tutr_I XM_022570428.1_Dele_I XM_004262104.1_Oror_ XM 007471701.1 Live XM_007192958.1_Baac_I
TTC ATC TAA TTT AGg ATA Agt TCT GAA CGT CGA AAA GAg AAg TCT AgA GAT GCA GCC AgA TCT CGA CGA AGT AAA GAG TTC ATC TAA TTT AGG ATA AGT TCT GAA CGT CGA AAA GAG AAG TCT AGA GAT GCA GCC AGA TCT CGA CGA AGT AAA GAG TTC ATC TAA TTT AGG ATA AGT TCT GAA CGT CGA AAA GAG AAg TCT AGA GAT GCA GCC AGA TCT CGA CGA AGT AAA GAG TTC ATC TAA TTT AGG ATA AGT TCT GAA CGT CGA AAA GAG AAG TCT AGA GAT GCA GCC AGA TCT CGA CGA AGT AAA GAG TTC ATC TAA TTT AGG ATA AGT TCT GAA CGT CGA AAA GAG AAG TCT AGA GAT GCA GCC AGA TCT CGT CGA AGT AAA GAG TTC ATC TAA CTT AGG ATA AGT TCT GAA CGT CGA AAA GAG AAG TCT AGA GAT GCA GCC AGA TCT CGT CGA AGT AAA GAG TTC ATC TAA TTT AGG ATA AGT TCT GAA CGT CGA AAA GAg AAg TCT AGA GAT GCA GCC AGA TCT CGT CGA AGT AAA GAG TTT TTG TTA AAT AGG ATA AGT TCT GAA CGT CGA AAA GAG AAA TCT AGA GAT GCA GCC AGA TCT CGA CGA AGT AAA GAG TTT TTG TTA AAT AGG ATA AGT TCT GAA CGT CGA AAA GAG AAA TCT AGA GAT GCA GCC AGA TCT CGA CGA AGT AAA GAG TTT TTG TTA AAT AGG ATA AGT TCT GAA CGT CGA AAA GAG AAA TCT AGA GAT GCA GCC AGA TCT CGA CGA AGT AAA GAG TGT CAA CTC TTG AGG ATA AGT TCT GAA CGT CGA AAA GAg AAg TCT AGA GAT GCA GCC AGA TCT CGT CGA AGT AAA GAG GTG CTC AAT AAA TGG ATA AGT TCT GAA CGT CGA AAA GAG AAG TCT AGA GAT GCA GCC AGA TCT CGA CGA AGT AAA GAG GTG CTT AGT GTG CTT AGT AAA TGG ATA AGT TCT GAA CGT CGA AAA GA AAG TCT AGA GAT GCA GCC AGA TCT CGT CGA AGT AAA GAG GTG CTT AGT AAA TGG ATA AGT TCT GAA CGT CGA AAA GAg AAg TCT AGA GAT GCA GCC AGA TCT CGT CGA AGT AAA GAG CTT TTT TCC ACC AAG ATA AGT TCT GAA CGT CGA AAA GAG AAA TCT AGA GAT GCA GCC AGA TCT CGT CGA AGT AAA GAG AAC GAC AAG AAA AAG ATA AGT TCT GAA CGT CGA AAA GAG AAA TCT AGA GAT GCA GCC AGA TCT CGT CGA AGT AAA GAG AAC GAC AAG AAA AAG ATA AGT TCG GAA CGT CGA AAA GAg AAg TCT AGA GAT GCA GCC AGA TCT CGT CGA AGT AAA GAG AAC GAC AAG AAA AAG ATA AGT TCT GAA CGT CGA AAA GAg AAG TCT AGA GAT GCA GCC AGA TCT CGT CGA AGT AAA GAG AAC GAC AAG AAA AAg ATA AGT TCT GAA CGT CGA AAA GAg AAg TCT AGA GAT GCA GCC AgA TCT CGT CGA AGT AAA GAG AAC GAC AAG AAA AAG ATA AGT TCT GAA CGT CGA AAA GAG AAG TCT AGA GAT GCA GCC AGA TCT CGT CGA AGT AAA GAG AAC GAC AAG AAA AAG ATA AGT TCT GAA CGT CGA AAA GA AAG TCT AGA GAT GCA GCC AGA TCT CGT CGA AGT AAA GAG AAC GAC AAG AAA AAG ATA AGT TCT GAA CGT CGA AAA GA AAG TCT AGA GAT GCA GCC AGA TCT CGT CGA AGT AAA GAG AAC GAC AAG AAA AAG ATA AGT TCT GAA CGT CGA AAA GAg AAg TCT AGA GAT GCA GCC AGA TCT CGT CGA AGT AAA GAG AAC GAC AAG AAA AAG ATA AGT TCT GAA CGT CGA AAA GAG AAg TCT AGA GAT GCA GCC AGA TCT CGT CGA AGT AAA GAG AAC GAC AAG AAA AAG ATA AGT TCT GAA CGT CGA AAA GAg AAA TCT AGA GAT GCA GCC AGA TCT CGA CGA AGT AAA GAG AAC GAC AAG AAA AAA ATA AGT TCT GAA CGT CGA AAA GAG AAG TCT AGA GAT GCA GCC AGA TCT CGA CGA AGT AAA GAG AAC GAC AAG AAA AAG ATA AGT TCT GAA CGT CGA AAA GAG AAG TCT AGA GAT GCA GCC AGA TCT CGA CGA AGT AAA GAG AAC GAC AAG AAA AAG ATG AGT TCT GAA CGT CGA AAA GAG AAG TCT AGA GAT GCA GCC AGA TCT CGA CGA AGT AAA GAG AAC GAC AAG AAA AAG ATA AGT TCT GAA CGT CGA AAA GAG AAG TCT AGA GAT GCA GCC AGA TCT CGA CGA AGT AAA GAG AAC GAC AAG AAA AAG ATA AGT TCT GAA CGT CGA AAA GAG AAG TCT AGA GAT GCA GCC AGA TCT CGA CGA AGT AAA GAG AAC GAC AAG AAA AAG ATA AGT TCT GAA CGT CGA AAA GAG AAg TCT AGA GAT GCA GCC AGA TCT CGA CGA AGT AAA GAG AAC GAC AAG AAA AAG ATA AGT TCT GAA CGT CGA AAA GAG AAG TCT AGA GAT GCA GCC AGA TCT CGA CGA AGT AAA GAG AAC GAC AAg AAA AAG ATA AGT TCT GAA CGT CGA AAA GAg AAg TCT AgA GAT GCA GCC AGA TCT CGA CGA AGT AAA GAG 


\section{CGA AAA GAG}

XM_007192959.1_Baac_S XM_022570429.1_Dele_. XM-007109894.2 Phca XM 019923097.1 Tutr XM-018053545.1-CahiXM-010847647.1-BiXM_010847647.1_Bibi_XM_020896418.1_Odvi_S ABRR02138382.1_Vipa_S JDVD01013070.1_Cadr_S AGVR01032341.1_Cafe_S XM 010847646.1 Bibi ${ }^{-}$ XM_007471699.1 Live XM 015097105.1 Ovar $\mathrm{XM}^{-} 010847645.1^{-} \mathrm{Bibi}^{-}$ DQ838048.1 Bogr L

XM_00596008̄5.1_Paho_L AY $\overline{9} 71808.1$ Pahō_ XM_01214725̄2.2_Ovar_I XM-020896417.1_Odvi_I

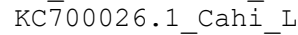
NM $174339 . \overline{3}$ Bota XM $01996902 \overline{4} .1$ Boin I XM 006054432.1 Bubu AY $\overline{6} 21118.1$ Bogr L XM_00589069̄4.1 Bomu_I XM_010962237.1_Caba_I NM_001123124.1_Susc_I KJ144249.1 Neas I KJ619998.1 ${ }^{-} \mathrm{PhCa}^{-}$ XM_0199230 $\overline{9} 3.1$ Tutr_L XM-022570428.1-Dele-I XM_004262104.1_Oror_I XM_007471701.1_Live_ XM_007192958.1_Baac_I
60

70

TCT GAA GTT TTT TAT GAg CTT GCT CAT CAg TTG CCA CTT CCC CAT AAC GTG AGC TCA CAT CTT GAT AAG GCT TCT GTT TCT GAA GTT TTT TAT GAG CTT GCT CAT CAg TTG CCA CTT CCC CAT AAT GTG AGC TCA CAT CTT GAT AAG GCT TCT GTT TCT GAA GTT TTT TAT GAG CTT GCT CAT CAG TTG CCA CTT CCC CAT AAT GTG AGC TCA CAT CTT GAT AAG GCT TCT GTT TCT GAA GTT TTT TAT GAG CTT GCT CAT CAG TTG CCA CTT CCC CAT AAT GTG AGC TCA CAT CTT GAT AAG GCT TCT GTT TCT GAA GTT TTT TAT GAG CTT GCT CAT CAG TTG CCG CTC CCC CAT AAT GTA AGC TCG CAT CTT GAT AAG GCT TCT GTT TCT GAA GTT TTT TAT GAG CTT GCT CAT CAG TTG CCA CTC CCC CAT AAT GTA AGC TCG CAT CTT GAT AAG GCT TCT GTT TCT GAA GTT TTT TAT GAG CTT GCT CAT CAG TTG CCA CTC CCT CAT AAT GTA AGC TCG CAT CTT GAT AAG GCT TCT GTT TCT GAA GTT TTT TAT GAG CTT GCT CAT CAG CTG CCA CTT CCC CAT AAT GTG AGC TCG CAT CTT GAT AAG GCT TCT GTT TCT GAA GTT TTT TAT GAG CTT GCT CAT CAG CTG CCA CTT CCC CAT AAT GTG AGC TCG CAT CTT GAT AAG GCT TCT GTT TCT GAA GTT TTT TAT GAG CTT GCT CAT CAG CTG CCA CTT CCC CAT AAT GTG AGC TCG CAT CTT GAT AAG GCT TCT GTT TCT GAA GTT TTT TAT GAG CTT GCT CAT CAG TTG CCA CTC CCC CAT AAT GTA AGC TCG CAT CTT GAT AAG GCT TCT GTT TCT GAA GTT TTT TAT GAG CTT GCT CAT CAG TTG CCA CTT CCC CAT AAT GTG AGC TCA CAT CTT GAT AAG GCT TCT GTT TCT GAA GTT TTT TAT GAG CTT GCT CAT CAG TTG CCA CTC CCC CAT AAT GTA AGC TCG CAT CTT GAT AAG GCT TCT GTT TCT GAA GTT TTT TAT GAG CTT GCT CAT CAG TTG CCA CTC CCC CAT AAT GTA AGC TCG CAT CTT GAT AAG GCT TCT GTT TCT GAA GTT TTT TAT GAG CTT GCT CAT CAG TTG CCA CTC CCC CAT AAT GTA AGC TCG CAT CTT GAT AAG GCT TCT GTT TCT GAA GTT TTT TAT GAG CTT GCT CAT CAG TTG CCA CTC CCC CAT AAT GTA AGC TCG CAT CTT GAT AAG GCT TCT GTT TCT GAA GTT TTT TAT GAG CTT GCT CAT CAG TTG CCA CTC CCC CAT AAT GTA AGC TCG CAT CTT GAT AAG GCT TCT GTT TCT GAA GTT TTT TAT GAG CTT GCT CAT CAG TTG CCA CTC CCC CAT AAT GTA AgC TCG CAT CTT GAT AAG GCT TCT GTT TCT GAA GTT TTT TAT GAG CTT GCT CAT CAG TTG CCA CTC CCT CAT AAT GTA AGC TCG CAT CTT GAT AAG GCT TCT GTT TCT GAA GTT TTT TAT GAG CTT GCT CAT CAG TTG CCG CTC CCC CAT AAT GTA AGC TCG CAT CTT GAT AAG GCT TCT GTT TCT GAA GTT TTT TAT GAG CTT GCT CAT CAG TTG CCA CTC CCC CAT AAT GTA AGC TCG CAT CTT GAT AAG GCT TCT GTT TCT GAA GTT TTT TAT GAG CTT GCT CAT CAG TTG CCA CTC CCC CAT AAT GTA AGC TCG CAT CTT GAT AAG GCT TCT GTT TCT GAA GTT TTT TAT GAG CTT GCT CAT CAG TTG CCA CTC CCC CAT AAT GTA AGC TCG CAT CTT GAT AAG GCT TCT GTT TCT GAA GTT TTT TAT GAG CTT GCT CAT CAG TTG CCA CTC CCC CAT AAT GTA AGC TCG CAT CTT GAT AAG GCT TCT GTT TCT GAA GTT TTT TAT GAG CTT GCT CAT CAG TTG CCA CTC CCC CAT AAT GTA AGC TCG CAT CTT GAT AAG GCT TCT GTT TCT GAA GTT TTT TAT GAG CTT GCT CAT CAG CTG CCA CTT CCC CAT AAT GTG AGC TCG CAT CTT GAT AAG GCT TCT GTT TCT GAA GTT TTT TAT GAG CTT GCT CAT CAG TTG CCA CTT CCC CAT AAT GTG AGC TCA CAT CTT GAT AAG GCT TCT GTT TCT GAG GTT TTT TAT GAg CTT GCT CAT CAG TTG CCA CTT CCC CAT AAT GTG AGC TCA CAT CTT GAT AAG GCT TCT GTT TCT GAA GTT TTT TAT GAG CTT GCT CAT CAG TTG CCA CTT CCC CAT AAT GTG AGC TCA CAT CTT GAT AAG GCT TCT GTT TCT GAA GTT TTT TAT GAG CTT GCT CAT CAG TTG CCA CTT CCC CAT AAT GTG AGC TCA CAT CTT GAT AAG GCT TCT GTT TCT GAA GTT TTT TAT GAG CTT GCT CAT CAG TTG CCA CTT CCC CAT AAT GTG AGC TCA CAT CTT GAT AAG GCT TCT GTT TCT GAA GTT TTT TAT GAG CTT GCT CAT CAG TTG CCA CTT CCC CAT AAT GTG AGC TCA CAT CTT GAT AAG GCT TCT GTT TCT GAA GTT ITT TAT GAG CIT GCT CAT CAG TIG CCA CIT CCC CAT AAT GTG AGC TCA CAT CIT GAT AAG GCI ICI GTT TCT GAA GTT TTT TAT GAg CTT GCT CAT CAg TTG CCA CTT CCC CAT AAC GTG AGC TCA CAT CTT GAT AAg GCT TCT GTT 